\title{
Aid Effectiveness of Aid for Trade: An Empirical Analysis on the Extensive and Intensive Margins of Aid Recipients
}

\author{
By Kunhyui Kim ${ }^{1}$
}

\begin{abstract}
Paris Declaration on Aid Effectiveness held in 2005 emphasized the role of Aid for Trade (AFT) on capacity building of developing nations. Past literature showed mixed results regarding the aid effectiveness of foreign aid both theoretically and empirically. To test the impact of foreign aid thoroughly, we first focus on the AFT which purposes are not only stimulating the volume of trade flow but also facilitating the construction of robust infrastructure and environment for developing nations to participate in the global economy independently. Second, we disaggregate bilateral trade into the extensive and intensive margin of international trade to examine whether AFT affects more on the new products traded or incumbent good. Lastly, we conduct Poisson pseudo maximum likelihood (PPML) estimation to control for zero-value observations and possible heteroskedasticity stemming from the sample. With different sample groups, the results indicate that AFT overall benefits the exports of aid recipients. Particularly, AFT from European Union (EU) shows the most considerable and consistent effect on both the new export and incumbent relationships. Furthermore, AFT from the EU facilitates the new export relationship between developing nations with other developing nations, specifically with those without a Free Trade Agreement (FTA) relationship, indicating that the aid from the EU is relatively effective in establishing new trade partners.
\end{abstract}

Keywords: aid effectiveness, aid-for-trade, foreign aid, PPML, the extensive and intensive margin of international trade

\section{Introduction}

The impact of foreign aid has aroused ongoing debates on its effectiveness. Burnside and Dollar (2000) and Gupta and Islam (2012) empirically showed the positive linkage between foreign aid and economic development. With the Big push Theory, Easterly (2006), Rosenstein-Rodan (1943, 1961), and Sachs (2005) also emphasized the role of foreign aid in alleviating the poverty traps of aid recipients. Samuelson (1947) further theoretically proved that as untied aid increases, the welfare of recipients would increase as well. On the other hand, theoretical models of Bhagwati et al. (1983) and Yano and Nugent (1999) state the small country transferparadox; untied aid may result in the welfare loss of recipients when import tariff is present.

As the multifarious relationship between foreign aid and economic development may result from mixed or unknown external forces, this research narrows down the spectrum of both foreign aid and economic development to test the aid effectiveness. We first adopt the Aid for Trade (hereafter, AFT) portion from aggregate foreign aid that was first 
proposed in the 2005 Paris Declaration. As the purpose of foreign aid is not a mere improvement of the current economic development of aid recipients but to establish robust infrastructure for future independence, the primary target of AFT lies in the capacity building of trade infrastructure. Furthermore, as the current fragmented system of production networks emphasizes the role of global value chains (GVCs), participating in trade activities for developing nations may be an excellent opportunity for them to drastically achieve economic growth. The fragmentation of production networks further implies relatively easier participation of developing nations with relatively small capital endowments or relatively lower manufacturing infrastructure (World Bank, 2019). Therefore, we focus on the trade activity of aid recipients and, at the same time, examine how AFT from aid donors facilitated or hampered the participation of aid recipients toward the global trade environment.

Series of past literature dealt with the relationship between AFT and international trade. Ghimire et al. (2013) and Hühne et al. (2014) found a positive linkage between AFT and exports of both donors and recipients. However, the magnitude was shallow for the export of recipients, suggesting the limited power of AFT. We further decompose the direction of exports from the aid recipients to examine whether the assistance received is employed more on the specific designation. As one of the criticisms of foreign aid is often the economic or political ties behind the assistance by specific donors, the direction of trade may capture the proper usage of foreign aid by the aid recipients.

To determine the aid effectiveness of AFT thoroughly, we incorporate the extensive and intensive margin of international trade to differentiate the new goods traded and the incumbent goods traded. As Helpman et al. (2008) emphasized, examining international trade volume alone may result in biased results as they lack the information on export diversification. In response to the emphasis, they constructed extensive margin as the number of sectors and conducted a two-stage Heckman selection model (Heckman, 1979). Feenstra (1994) and Hummels and Klenow (2005) defined the extensive and the intensive margin as the number of exported products and volume relative to the world traded portion. To take account of the trade participation of aid recipients relative to the world trend, we adopt the methodology of Feenstra (1994) and Hummels and Klenow (2005) to construct the extensive and intensive margin of international trade.

Only a handful of research focused on the aid effectiveness of AFT on disaggregated components of international trade. Kim (2012) adopted the Herfindahl-Hirschman index (HHI) to denote export diversification. Our research deviates from her research as we adopt a theoretically grounded structure of decomposing international trade into new goods traded and incumbent goods traded from Hummels and Klenow (2005). Unlike Kim (2012), we further employ Poisson Pseudo Maximum Likelihood (PPML) estimation to adjust for zero observation of trade and to adjust for possible heteroskedasticity (Silva and Tenreyro, 2006). We assume zero trade value when there exists a foreign aid but no reported traded value. We take account of the AFT that were not employed in export activities to examine the effectiveness of foreign aid thoroughly.

The rest of the paper is as follows. We present the empirical framework and the data in Sections 2 and 3. In Section 5, we present the empirical results of our analysis. We conclude the paper with Section 6. 


\section{Empirical Framework}

We present the empirical model in this section. With the traditional gravity model, we assume international trade as a function of Gross Domestic Product (GDP) per capita and distance. GDP per capita represents the size of the market and distance as trade costs. We incorporate foreign aid into the model as an external shock that affects the volume of trade.

Trade $_{i j t}=\beta_{0}+\beta_{1} A F T_{i t}^{\text {Total }}+\beta_{2} \operatorname{lnGDPPC} C_{j t}+\beta_{3} \operatorname{lnGDPPC} C_{i t}+\beta_{4} \operatorname{lnDistance}_{i j}+\delta_{i j}+\varphi_{i j t}$

Trade $_{i j t}=\beta_{0}+\beta_{1} A F T_{i t}^{D A C}+\beta_{2} \operatorname{lnGDPPC} C_{j t}+\beta_{3} \operatorname{lnGDPPC} C_{i t}+\beta_{4} \operatorname{lnDistance}_{i j}+\delta_{i j}+\varphi_{i j t}$

Trade $_{i j t}$ refers to the export value from aid recipient $i$ to corresponding partner $j$ at time t. $A F T_{i t}^{\text {Total }}$ and $A F T_{i t}^{D A C}$ indicate the disbursement AFT from total donors and DAC members, respectively, to aid recipients $i . \ln G D P P C_{j t}$ and $\ln G D P P C_{i t}$ refer to the natural logarithm of GDP per capita for each trading partner and aid recipient at time $t$. lnDistance $_{i j}$ denotes the natural logarithm of the distance between $i$ and $j$. To take account of the zero observations of trade and AFT, we employ the raw value. $\delta_{i j}$ and $\varphi_{i j t}$ indicate time-invariant and time-variant error terms.

Next, we disaggregate Trade $_{i j t}$ as the extensive and intensive margin following Feenstra (1994), Hummels and Klenow (2005), and Feenstra and Kee (2008). They construct the extensive margin as a count of exported products from country $i$ to $j$ relative to the world average and the intensive margin as the nominal exports from $i$ to $j$ relative to the world exports to $j$. Thus, the extensive margin captures the new export relationship from $i$ to $j$, whereas the intensive margin depicts the trade growth of incumbent goods exported from $i$ to $j$. We consider HS six-digit products $p$ as differentiated products of HS two-digit sectors $s$ at time $t$. We define the extensive margin as:

$E M_{i j t}^{S}=\frac{\sum_{p \in P_{i j t}^{S}} v_{k j p t} q_{k j p t}}{\sum_{p \in P_{k j t}^{s}} v_{k j p t} q_{k j p t}}$

where $P_{i j t}^{S}$ refers to the product categories from $i$ to $j$ in sector $s$ at time $t . P_{k j t}^{S}$ indicates the product categories from reference country $k$ to $j$, where we define $k$ as the aggregated value of our total sample. We further construct the intensive margin as:

$I M_{i j t}^{S}=\frac{\sum_{p \in P_{i j t}^{S}} v_{i j p t} q_{i j p t}}{\sum_{p \in P_{i j t}^{s}} v_{k j p t} q_{k j p t}}$

which examines the nominal exports from $i$ to $j$ in sector $s$ at time $t$. As we define Trade $_{i j t}^{S}=\sum_{p \in P_{i j t}^{S}} v_{i j p t} q_{i j p t}$, we decompose Trade ${ }_{i j t}^{S}$ as:

Trade $_{i j t}^{S}=E M_{i j t}^{S} I M_{i j t}^{s} \sum_{p \in P_{k j t}^{s}} v_{k j p t} q_{k j p t}$

where $\sum_{p \in P_{k j t}^{s}} v_{k j p t} q_{k j p t}$ refers to the world exports of $P_{k j t}^{S}$ to destination $j$. Equation (5) verifies that bilateral export serves as an aggregate term of two margins and the world exports. As our research focus on the bilateral export decision of aid recipients, we decompose equations (1) and (2) using the extensive and intensive margins, which are shown as:

$E M_{i j t}=\beta_{0}+\beta_{1} A F T_{i t}^{\text {Total }}+\beta_{2} \operatorname{lnGDPPC} C_{j t}+\beta_{3} \operatorname{lnGDPPC} C_{i t}+\beta_{4} \operatorname{lnDistance}_{i j}+\delta_{i j}+\varphi_{i j t}$

$I M_{i j t}=\beta_{0}+\beta_{1} A F T_{i t}^{\text {Total }}+\beta_{2}$ InGDPPC $_{j t}+\beta_{3} \operatorname{lnGDPPC}_{i t}+\beta_{4}$ lnDistance $_{i j}+\delta_{i j}+\varphi_{i j t}$

$E M_{i j t}=\beta_{0}+\beta_{1} A F T_{i t}^{D A C}+\beta_{2} \operatorname{lnGDPPC} C_{j t}+\beta_{3} \operatorname{lnGDPPC} C_{i t}+\beta_{4} \operatorname{lnDistance} e_{i j}+\delta_{i j}+\varphi_{i j t}$ 
$I M_{i j t}=\beta_{0}+\beta_{1} A F T_{i t}^{D A C}+\beta_{2} \ln G D P P C_{j t}+\beta_{3} \operatorname{lnGDPPC} C_{i t}+\beta_{4}$ lnDistance $_{i j}+\delta_{i j}+\varphi_{i j t}$

where $E M_{i j t}$ and $I M_{i j t}$ are aggregated margins of international trade using bilateral trade shares as weights. We further decompose $A F T_{i j t}$ using the shares of three large foreign aid donors: EU, USA, and Japan.

$E M_{i j t}=\beta_{0}+\beta_{1}\left(\gamma_{1} A F T_{i t}^{E U}+\gamma_{2} A F T_{i t}^{U S A}+\gamma_{3} A F T_{i t}^{J P N}\right)+\beta_{2} \ln G D P P C_{j t}+\beta_{3} \ln G D P P C_{i t}+$ $\beta_{4}$ lnDistance $_{i j}+\delta_{i j}+\varphi_{i j t}$

$I M_{i j t}=\beta_{0}+\beta_{1}\left(\gamma_{1} A F T_{i t}^{E U}+\gamma_{2} A F T_{i t}^{U S A}+\gamma_{3} A F T_{i t}^{J P N}\right)+\beta_{2} \ln G D P P C_{j t}+\beta_{3} \operatorname{lnGDPPC_{it}}+$ $\beta_{4}$ lnDistance $_{i j}+\delta_{i j}+\varphi_{i j t}$

$A F T_{i j t}^{E U}$ indicates AFT from EU, $A F T_{i j t}^{U S A}$ refers to AFT from the USA, and $A F T_{i j t}^{J P N}$ expresses AFT from Japan. We mainly focus on the export outflow from aid recipients to non-DAC members to exclude the possible impact of political and economic ties behind the foreign aid of each donor. We then expand the regressions with different directions to further examine whether each AFT genuinely captures any political and economic ties with donor countries: exports from aid recipients to different aid recipients, DAC members, and all sample countries.

Furthermore, we examine whether aid effectiveness appears more on the trade relationship that aid recipients already have. We construct interaction term using AFT variables and the dummy variable for the Free Trade Agreement (FTA) relationship. The variables capture whether aid recipients utilize foreign aid from each major donor to boost the incumbent relationship or to penetrate new markets. The equations are as follows:

$E M_{i j t}=\beta_{0}+\beta_{1}\left(\gamma_{1} A F T_{i t}^{E U} * F T A_{i j t}+\gamma_{2} A F T_{i t}^{U S A} * F T A_{i j t}+\gamma_{3} A F T_{i t}^{J P N} * F T A_{i j t}+\gamma_{4} A F T_{i t}^{E U} *\right.$

$\left.\left(F T A_{i j t}-1\right)+\gamma_{5} A F T_{i t}^{U S A} *\left(F T A_{i j t}-1\right)+\gamma_{6} A F T_{i t}^{J P N} *\left(F T A_{i j t}-1\right)\right)+\beta_{2} \ln G D P P C_{j t}+$

$\beta_{3} \operatorname{lnGDPPC}_{i t}+\beta_{4}$ lnDistance $_{i j}+\delta_{i j}+\varphi_{i j t}$

$I M_{i j t}=\beta_{0}+\beta_{1}\left(\gamma_{1} A F T_{i t}^{E U} * F T A_{i j t}+\gamma_{2} A F T_{i t}^{U S A} * F T A_{i j t}+\gamma_{3} A F T_{i t}^{J P N} * F T A_{i j t}+\gamma_{4} A F T_{i t}^{E U} *\right.$

$\left.\left(F T A_{i j t}-1\right)+\gamma_{5} A F T_{i t}^{U S A} *\left(F T A_{i j t}-1\right)+\gamma_{6} A F T_{i t}^{J P N} *\left(F T A_{i j t}-1\right)\right)+\beta_{2} \ln G D P P C_{j t}+$

$\beta_{3} \ln G D P P C_{i t}+\beta_{4}$ lnDistance $_{i j}+\delta_{i j}+\varphi_{i j t}$

Here, $\beta_{1} \gamma_{1}, \beta_{1} \gamma_{2}$, and $\beta_{1} \gamma_{3}$ capture the effect of AFT from major donors when aid recipients and their corresponding partners have an FTA relationship, whereas $\beta_{1} \gamma_{4}$, $\beta_{1} \gamma_{5}$, and $\beta_{1} \gamma_{6}$ capture the effect of AFT from major donors when aid recipients and their corresponding partners lack a pre-economic relationship.

\section{Data}

We extract AFT data from the Organization for Economic Co-operation and Development (OECD) Structural Analysis (STAN) Database Creditor Reporting System (CRS). According to OECD, AFT includes Technical Assistance for trade policy and regulations, Economic infrastructure, Productive capacity building, and Trade-related adjustment. Appendix A describes the specific CRS code for each category. We aggregated the AFT from each donor to construct AFT variables: from the total sample, DAC members, EU, USA, and Japan. Appendix B shows 188 total sample countries and DAC members utilized in this research. AFT variables are weighted using bilateral trade shares to adjust for different amounts of foreign aid utilized for the exports from aid recipients to their corresponding export markets. Dependent variables of this research adopt HS 2002 nomenclature export value from UN Comtrade. We use both nominal terms for the export data and foreign aid data reported at 
the current billion US dollars from 2010 to 2018. We construct the extensive and intensive margin with HS six-digit products within the HS two-digit sectors. We then aggregate both margins using bilateral trade shares to correspond with country-level AFT variables.

GDP per capita for each $i$ and $j$ are from World Development Indicator (WDI). We extract population-weighted distance from the Centre d' Etudes Prospectives et d' Informations Internationales (CEPII) database. FTA relationships for the interaction term originate from the World Trade Organization (WTO) Regional Trade Agreement (RTA) database.

Before proceeding to empirical results, we present summary statistics of our data. As we focus on the impact of AFT on the international trade environment of aid recipients to non-aid donors, Table 1 depicts the sample where the aid recipients engage in exports to non-DAC members.

Table 1. Summary Statistics (Exports from aid recipients to non-aid donors)

\begin{tabular}{lccccc}
\hline & $(1)$ & $(2)$ & $(3)$ & $(4)$ & $(5)$ \\
VARIABLES & $\mathrm{N}$ & Mean & SD & Min & Max \\
\hline Trade value & 122,975 & 0.0883 & 1.143 & 0 & 99.36 \\
Extensive Margin & 122,975 & 0.0642 & 0.157 & 0 & 1 \\
Intensive Margin & 122,975 & 0.0253 & 0.101 & 0 & 1 \\
GDP per capita () & 122,975 & 0.0175 & 0.0872 & 0.000211 & 1.015 \\
GDP per capita $(i)$ & 122,975 & 0.00895 & 0.0369 & 0.000211 & 1.978 \\
Distance & 122,975 & 7,686 & 4,625 & 60.77 & 19,667 \\
AFT from total donors & 122,975 & 0.000696 & 0.00755 & 0 & 0.617 \\
AFT from DAC & 122,975 & 0.000649 & 0.00720 & 0 & 0.617 \\
AFT from EU & 122,975 & 0.000231 & 0.00251 & 0 & 0.194 \\
AFT from USA & 122,975 & 0.000107 & 0.00211 & 0 & 0.286 \\
AFT from Japan & 122,975 & 0.000250 & 0.00422 & 0 & 0.436 \\
\hline
\end{tabular}

*Note: $N$ refers to the total observations, SD refers to the standard deviation, Min refers to the minimum value, and Max refers to the maximum value. GDP per capita and distance are presented with the raw value. Trade value, GDP per capita, and AFT variables are expressed in current billion US dollars. AFT variables are aggregate disbursement from respective donors. Summary statistics of other samples and correlation tables may be presented upon request.

As Table 1 indicates, the maximum AFT from the EU is relatively smaller than those from the USA and Japan. In contrast, the total aggregated amount of AFT from the EU is more prominent than those from Japan, according to OECD. AFT from the EU is relatively dispersed through different countries, whereas AFT from Japan is concentrated on particular destinations. We further conduct empirical regressions to examine whether the different nature of AFT from each aid donor manipulates or prompts export activities of aid recipients.

\section{Result}

We present empirical regression results using PPML in this section. Table 2 shows the baseline results using equations (1), (2), (6), (7), (8), and (9) with samples demonstrated in Table 1. EM and IM indicate the extensive and intensive margin of international trade, respectively. To control for year trends stemming from nominal data, we include year fixed effect. 
Table 2. Baseline PPML Regression Results (Recipients to non-DAC members)

\begin{tabular}{lcccccc}
\hline & $(1)$ & $(2)$ & $(3)$ & $(4)$ & $(5)$ & $(6)$ \\
VARIABLES & Value & Value & EM & EM & IM & IM \\
\hline AFT from total donors & $5.501^{* * *}$ & & $4.013^{* * *}$ & & $7.214^{* * *}$ \\
& $(0.690)$ & & $(0.438)$ & & $(0.757)$ & \\
AFT from DAC & & $5.623^{* * *}$ & & $4.237^{* * *}$ & & $7.638^{* * *}$ \\
& & $(0.745)$ & & $(0.460)$ & & $(0.774)$ \\
Log of GDP per capita $(j)$ & 0.186 & 0.180 & $-0.393^{* * *}$ & $-0.393^{* * *}$ & $-0.619^{* * *}$ & $-0.619^{* * *}$ \\
& $(0.287)$ & $(0.287)$ & $(0.090)$ & $(0.090)$ & $(0.143)$ & $(0.143)$ \\
Log of GDP per capita (i) & $1.367^{* * *}$ & $1.361^{* * *}$ & $-0.225^{* * *}$ & $-0.226^{* * *}$ & -0.164 & -0.164 \\
& $(0.207)$ & $(0.208)$ & $(0.083)$ & $(0.083)$ & $(0.154)$ & $(0.154)$ \\
Log of Distance & $-0.760^{* * *}$ & $-0.762^{* * *}$ & $0.524^{* * *}$ & $0.524^{* * *}$ & $0.541^{* * *}$ & $0.541^{* * *}$ \\
& $(0.021)$ & $(0.021)$ & $(0.010)$ & $(0.010)$ & $(0.015)$ & $(0.015)$ \\
Constant & $13.532^{* * *}$ & $13.501^{* * * *}$ & $-10.491^{* * *}$ & $-10.493^{* * *}$ & $-12.374 * * *$ & $-12.375^{* * *}$ \\
& $(1.259)$ & $(1.258)$ & $(0.655)$ & $(0.655)$ & $(1.183)$ & $(1.183)$ \\
Observations & 122,975 & 122,975 & 122,975 & 122,975 & 122,975 & 122,975 \\
Country FE & YES & YES & YES & YES & YES & YES \\
Year FE & YES & YES & YES & YES & YES & YES \\
Log Likelihood & -13952 & -13953 & -24406 & -24406 & -11640 & -11640 \\
Pseudo R-squared & 0.718 & 0.718 & 0.103 & 0.103 & 0.143 & 0.143 \\
\hline Robust standard errors in parentheses;*** $p<0.01, * * p<0.05, * p<0.1$ & &
\end{tabular}

Trade value and the extensive and intensive margin of outflow exports of aid recipients are all positively related to AFT from total donors and DAC. Unlike the past theoretical and empirical research on the aid effectiveness of foreign aid, Table 2 indicates the positive and statistically significant impact of foreign aid with a particular intent on the economic development of aid recipients. Compared to the coefficients of AFT from total donors, coefficients of AFT from DAC showed a larger magnitude. For example, a one billion US dollar increase in foreign aid facilitated the outflow exports of the aid recipients to nonDAC members by 5.6 billion US dollars, and the ratio of extensive and intensive margin by 4.2 and 7.6 percent, respectively. On the other hand, AFT from total donors resulted in a 5.5 billion US dollars increase in exports, and 4.0 and 7.2 percent increase in extensive and intensive margin. Nevertheless, no signs of explicit misuse of AFT from non-DAC members were captured. Inclusion of AFT from non-DAC members showed a less or ignorable amount of economic and political-tied assistance from the donors.

The traditional implication of iceberg costs also showed opposite results for both the extensive and intensive margin of international trade. Traditional models of international trade often employ distance as iceberg costs, which are proportional trade costs stemming from the shipments of goods. Indeed, distance on total trade value is negative and statistically significant, indicating that among numbers of trading partners, partners located in one percent farther distance compared to another partner would hamper exports by seven million US dollars. However, the natural logarithm of the distance and the extensive and intensive margin of international trade is positively related, with statistical significance. The negative relationship may imply that the decision of exporters to either penetrate the new market or extend the current trading partners is proportional to the trade costs. To correspond with higher proportional costs, exporters diversify the products (extensive margin) and enlarge the volume of incumbent goods (intensive margin) to compensate for 
additional costs. Nevertheless, higher iceberg costs, at last, hamper the aggregated value of exports. Further research with product-level input-output data may examine the relationship between trade costs and the strategies of firms more thoroughly. We leave the gap to future theoretical and empirical research.

We then disaggregate AFT from total DAC with AFT from EU, USA, and Japan, respectively, as shown in equations (10) and (11). The empirical results are shown in Tables 3 and 4.

Table 3. PPML results on the disaggregated sample (Extensive Margin)

\begin{tabular}{lcccc}
\hline \multirow{2}{*}{ VARIABLES } & $(1)$ & $(2)$ & $(3)$ & $(4)$ \\
\hline AFT from EU & EM & EM & EM & EM \\
AFT from USA & $7.024^{* * *}$ & $8.538^{* * *}$ & $8.110^{* * *}$ & $7.880^{* * *}$ \\
& $(1.539)$ & $(1.590)$ & $(1.319)$ & $(1.420)$ \\
AFT from Japan & 1.866 & 1.135 & $5.668^{* * *}$ & $2.151^{*}$ \\
& $(1.208)$ & $(1.674)$ & $(1.820)$ & $(1.168)$ \\
Log of GDP per capita $(j)$ & $3.838^{* * *}$ & $3.391^{* * *}$ & $1.604^{*}$ & $4.529^{* * *}$ \\
& $(0.809)$ & $(0.944)$ & $(0.954)$ & $(0.859)$ \\
Log of GDP per capita $(i)$ & $-0.393^{* * *}$ & $-0.545^{* * *}$ & 0.029 & $-0.384^{* * *}$ \\
& $(0.090)$ & $(0.184)$ & $(0.204)$ & $(0.087)$ \\
Log of Distance & $-0.226^{* * *}$ & -0.010 & 0.041 & $-0.205^{* * *}$ \\
& $(0.083)$ & $(0.122)$ & $(0.140)$ & $(0.075)$ \\
Constant & $0.523^{* * *}$ & $0.330^{* * *}$ & $0.361 * * *$ & $0.522^{* * *}$ \\
& $(0.010)$ & $(0.033)$ & $(0.038)$ & $(0.009)$ \\
Observations & $-10.494 * * *$ & $-7.947 * * *$ & $-6.178^{* * *}$ & $-10.332^{* * *}$ \\
Country FE & $(0.655)$ & $(0.777)$ & $(0.705)$ & $(0.607)$ \\
Year FE & 122,975 & 52,146 & 34,991 & 156,747 \\
Log Likelihood & YES & YES & YES & YES \\
Pseudo R-squared & YES & YES & YES & YES \\
\hline
\end{tabular}

Robust standard errors in parentheses; ${ }^{* * *} p<0.01,{ }^{* *} p<0.05,{ }^{*} p<0.1$

Table 4. PPML results on the disaggregated sample (Intensive Margin)

\begin{tabular}{lcccc}
\hline \multirow{2}{*}{ VARIABLES } & $(1)$ & $(2)$ & $(3)$ & $(4)$ \\
\hline AFT from EU & IM & IM & IM & IM \\
& $18.146^{* * *}$ & $14.184^{* * *}$ & $14.964^{* * *}$ & $19.062^{* * *}$ \\
AFT from USA & $(2.544)$ & $(2.464)$ & $(2.538)$ & $(2.379)$ \\
& $6.796^{* * *}$ & $4.977^{*}$ & $8.821^{* *}$ & $7.432^{* * *}$ \\
AFT from Japan & $(2.156)$ & $(2.596)$ & $(3.636)$ & $(2.093)$ \\
& $2.349 *$ & $4.929 * * *$ & $5.239^{* * *}$ & $3.240^{* *}$ \\
Log of GDP per capita $(j)$ & $(1.289)$ & $(1.609)$ & $(1.793)$ & $(1.354)$ \\
& $-0.620^{* * *}$ & 0.060 & 0.102 & $-0.609^{* * *}$ \\
Log of GDP per capita $(i)$ & $(0.143)$ & $(0.453)$ & $(0.649)$ & $(0.142)$ \\
& -0.164 & 0.422 & 0.359 & -0.145 \\
Log of Distance & $(0.154)$ & $(0.271)$ & $(0.322)$ & $(0.145)$ \\
& $0.542^{* * *}$ & 0.118 & $0.227 * * *$ & $0.546^{* * *}$ \\
Constant & $(0.015)$ & $(0.080)$ & $(0.087)$ & $(0.015)$ \\
& $-12.385^{* * *}$ & -2.457 & $-4.079 * *$ & $-12.254^{* * *}$
\end{tabular}




\begin{tabular}{lcccc}
\hline & $(1)$ & $(2)$ & $(3)$ & $(4)$ \\
VARIABLES & IM & IM & IM & IM \\
\hline Observations & 122,975 & 52,146 & 34,991 & 156,747 \\
Country FE & YES & YES & YES & YES \\
Year FE & YES & YES & YES & YES \\
Log Likelihood & -11640 & -1811 & -869.4 & -12504 \\
Pseudo R-squared & 0.143 & 0.143 & 0.150 & 0.161 \\
\hline
\end{tabular}

Robust standard errors in parentheses; *** $p<0.01$, ** $p<0.05$, * $p<0.1$

In Tables 3 and 4, columns (1) to (4) indicate different samples. Sample (1) refers to the identical sample used in Table 1; exports from aid recipients to non-DAC members. Sample (2) indicates exports from aid recipients to other aid recipients. Sample (3) depicts exports from aid recipients to DAC members. Lastly, Sample (4) refers to exports from aid recipients to all trade partners. All AFT variables positively affect both the extensive and intensive margin of international trade, excluding AFT from the USA on the extensive margin of trade via recipient to non-DAC and different aid recipient economies. The result implies that AFT from the USA is relatively more effective in incurring different products to aid donors than non-aid donors. Aid donors, including the USA, may benefit the most from the AFT from USA as aid recipients are tied to establishing more export relationships with a relatively developed world. Noticeably, AFT from the EU unparallelly affects exports with an immense magnitude and consistent coefficients (with the strongest statistically significant result). The results are unchanged throughout all samples. The implication is clear and explicit. Foreign aid designated to facilitate international trade activity of the aid recipients undoubtfully increase the export of aid recipients, and at the same time, the foreign aid from the EU acts as the most effective assistance.

Lastly, we conduct regressions using AFT variables and FTA dummies as shown in equations (12) and (13). FTA interacted AFT variables capture whether the AFT from each prominent aid donor is employed more on the channels where the recipients already have a connection. Columns (1) to (4) in Tables 5 and 6 indicate the samples depicted in Tables 3 and 4.

Table 5. PPML results on the disaggregated sample using FTA interaction term (Extensive Margin)

\begin{tabular}{lcccc}
\hline & $(1)$ & $(2)$ & $(3)$ & $(4)$ \\
VARIABLES & EM & EM & EM & EM \\
\hline AFT from EU * FTA & -2.450 & $12.259^{* * *}$ & $10.508^{* * *}$ & $5.904^{* *}$ \\
& $(4.579)$ & $(2.255)$ & $(2.177)$ & $(2.684)$ \\
AFT from EU * (1-FTA) & $8.967^{* * *}$ & $7.743^{* * *}$ & $7.382^{* * *}$ & $8.869^{* * *}$ \\
& $(1.561)$ & $(1.814)$ & $(1.511)$ & $(1.549)$ \\
AFT from USA * FTA & -1.152 & 1.486 & $9.234^{*}$ & $-3.098^{*}$ \\
& $(2.088)$ & $(4.902)$ & $(4.724)$ & $(1.864)$ \\
AFT from USA * (1-FTA) & $3.660^{*}$ & 1.324 & $5.733^{* * *}$ & $3.788^{* *}$ \\
& $(1.908)$ & $(1.703)$ & $(1.861)$ & $(1.720)$ \\
AFT from Japan * FTA & $14.093^{* * *}$ & $4.677^{* * *}$ & 2.366 & $12.270^{* * *}$ \\
& $(2.284)$ & $(1.607)$ & $(1.532)$ & $(1.547)$ \\
AFT from Japan * (1-FTA) & $2.246^{* * *}$ & $3.465^{* * *}$ & 1.644 & $3.508^{* * *}$ \\
& $(0.755)$ & $(1.008)$ & $(1.017)$ & $(0.896)$ \\
Log of GDP per capita $(j)$ & $-0.393^{* * *}$ & $-0.543^{* * *}$ & 0.033 & $-0.384^{* * *}$ \\
& $(0.090)$ & $(0.184)$ & $(0.204)$ & $(0.087)$
\end{tabular}




\begin{tabular}{lcccc}
\hline & $(1)$ & $(2)$ & $(3)$ & $(4)$ \\
VARIABLES & EM & EM & EM & EM \\
\hline Log of GDP per capita $(\imath)$ & $-0.227^{* * *}$ & -0.009 & 0.042 & $-0.206^{* * *}$ \\
& $(0.083)$ & $(0.122)$ & $(0.140)$ & $(0.075)$ \\
Log of Distance & $0.523^{* * *}$ & $0.331^{* * *}$ & $0.362^{* * *}$ & $0.522^{* * *}$ \\
& $(0.010)$ & $(0.034)$ & $(0.039)$ & $(0.009)$ \\
Constant & $-10.498^{* * *}$ & $-7.942^{* * *}$ & $-6.166^{* * *}$ & $-10.336^{* * *}$ \\
& $(0.656)$ & $(0.777)$ & $(0.706)$ & $(0.607)$ \\
Observations & 122,975 & 52,146 & 34,991 & 156,747 \\
Country FE & YES & YES & YES & YES \\
Year FE & YES & YES & YES & YES \\
Log Likelihood & -24405 & -6364 & -3582 & -27903 \\
Pseudo R-squared & 0.103 & 0.0944 & 0.0811 & 0.110 \\
\hline Robust stand & & & &
\end{tabular}

Robust standard errors in parentheses; *** $p<0.01,{ }^{* *} p<0.05,{ }^{*} p<0.1$

Table 6. PPML results on the disaggregated sample using FTA interaction term (Intensive Margin)

\begin{tabular}{|c|c|c|c|c|}
\hline & (1) & (2) & (3) & (4) \\
\hline VARIABLES & IM & $\mathrm{IM}$ & IM & $\mathrm{IM}$ \\
\hline AFT from EU $*$ FTA & $\begin{array}{c}25.597 * * * \\
(6.199)\end{array}$ & $\begin{array}{c}26.688^{* * *} \\
(3.527)\end{array}$ & $\begin{array}{c}25.625^{* * *} \\
(3.604)\end{array}$ & $\begin{array}{c}23.762^{* * *} \\
(3.397)\end{array}$ \\
\hline AFT from EU $*(1-F T A)$ & $\begin{array}{c}17.733^{* * *} \\
(2.677)\end{array}$ & $\begin{array}{c}13.305^{* * *} \\
(2.509)\end{array}$ & $\begin{array}{c}13.745^{* * * *} \\
(2.597)\end{array}$ & $\begin{array}{c}18.716^{* * * *} \\
(2.594)\end{array}$ \\
\hline AFT from USA $*$ FTA & $\begin{array}{l}-3.468 \\
(4.019)\end{array}$ & $\begin{array}{l}-39.523 \\
(34.280)\end{array}$ & $\begin{array}{c}14.974^{*} \\
(8.863)\end{array}$ & $\begin{array}{l}-2.848 \\
(3.717)\end{array}$ \\
\hline AFT from USA * (1-FTA) & $\begin{array}{c}8.941 * * * \\
(2.933)\end{array}$ & $\begin{array}{c}5.277 * * \\
(2.605)\end{array}$ & $\begin{array}{c}9.104^{* *} \\
(3.642)\end{array}$ & $\begin{array}{c}9.484 * * * \\
(2.858)\end{array}$ \\
\hline AFT from Japan * FTA & $\begin{array}{c}15.039 * * * \\
(2.828)\end{array}$ & $\begin{array}{c}11.838^{* * *} \\
(3.848)\end{array}$ & $\begin{array}{c}10.350^{* * * *} \\
(3.583)\end{array}$ & $\begin{array}{c}15.594 * * * \\
(2.108)\end{array}$ \\
\hline AFT from Japan * (1-FTA) & $\begin{array}{c}1.070 \\
(1.379)\end{array}$ & $\begin{array}{c}4.867 * * * \\
(1.680)\end{array}$ & $\begin{array}{c}5.139 * * * \\
(1.875)\end{array}$ & $\begin{array}{c}2.266 \\
(1.488)\end{array}$ \\
\hline Log of GDP per capita (j) & $\begin{array}{c}-0.621 * * * \\
(0.143)\end{array}$ & $\begin{array}{c}0.062 \\
(0.453)\end{array}$ & $\begin{array}{c}0.110 \\
(0.649)\end{array}$ & $\begin{array}{c}-0.610^{* * *} \\
(0.142)\end{array}$ \\
\hline Log of GDP per capita $(i)$ & $\begin{array}{l}-0.164 \\
(0.154)\end{array}$ & $\begin{array}{c}0.424 \\
(0.271)\end{array}$ & $\begin{array}{c}0.363 \\
(0.322)\end{array}$ & $\begin{array}{l}-0.145 \\
(0.146)\end{array}$ \\
\hline Log of Distance & $\begin{array}{c}0.542 * * * \\
(0.015)\end{array}$ & $\begin{array}{c}0.121 \\
(0.081)\end{array}$ & $\begin{array}{c}0.231 * * * \\
(0.088)\end{array}$ & $\begin{array}{c}0.546 * * * \\
(0.015)\end{array}$ \\
\hline Constant & $\begin{array}{c}-12.390^{* * *} \\
(1.183)\end{array}$ & $\begin{array}{l}-2.459 \\
(2.023)\end{array}$ & $\begin{array}{c}-4.066^{* *} \\
(2.055)\end{array}$ & $\begin{array}{c}-12.258^{* * *} \\
(1.135)\end{array}$ \\
\hline Observations & 122,975 & 52,146 & 34,991 & 156,747 \\
\hline Country FE & YES & YES & YES & YES \\
\hline Year FE & YES & YES & YES & YES \\
\hline Log Likelihood & -11640 & -1811 & -869.3 & -12504 \\
\hline Pseudo R-squared & 0.143 & 0.143 & 0.150 & 0.162 \\
\hline
\end{tabular}

Robust standard errors in parentheses; ${ }^{* * *} p<0.01,{ }^{* *} p<0.05,{ }^{*} p<0.1$

The existence of the FTA relationship yields mixed results among AFT variables. Overall, AFT from the EU benefits both the extensive and intensive margin when the FTA relationship is present between the aid recipients and the corresponding trade partners. 
Each aid recipients utilize foreign aid through channels that they already have a relationship with, which will be comparatively more accessible and cost-effective. However, the extensive margin of exports from aid recipients to different aid recipients only shows statistically significant coefficients when they do not have FTA relationships with corresponding partners. The result may indicate two implications. First, AFT from the EU may contribute to establishing infrastructure or an environment that enables aid recipients to participate in the global network independently and more efficiently. Thus, aid recipients utilize the foreign aid received from the EU to seek different lucrative markets for higher profits. Second, the FTA relationship between developing countries may not be effective compared to those involving developed countries. As aid recipients are primarily developing nations, the comparative advantage of the exported goods often represents primary or raw products. Tariff reductions via FTA where both countries export primary or raw goods benefit less from FTA between countries that export primary goods and manufactured products, as the former already have a similar comparative advantage. Either way, we find high linkages between AFT from the EU and the extensive and intensive margin, particularly those without FTA relationships.

The interaction term between AFT from the USA and Japan, and FTA relationships show mixed results. Similar to Table 3, foreign aid from the USA incurs new trade relationships to the DAC members, regardless of the FTA relationships. Furthermore, FTA relationships do not affect the foreign aid volume and decision from Japan much. However, compared to the AFT from the USA, AFT from Japan contribute more toward trade relationships between developing countries, indicating less economic or political ties behind the foreign aid.

\section{Conclusion}

Disaggregating the foreign aid by major aid donors and utilizing PPML to adjust for the zero trade values, this research intends to examine the aid effectiveness of AFT on the trade environment of aid recipients. By disaggregating the exports of aid recipients to new trade relationships and the growth rate of incumbent trade relationships, we find that AFT positively affects the export decisions of aid recipients generally. AFT from the EU notably showed significant and consistent results toward both the extensive and intensive margin of aid recipients and non-economical and -political ties behind the foreign aid.

Our research inevitably faces some shortcomings that future research may consider. First, sector-level, product-level, or even firm-level analysis would enhance the understanding of both AFT and the margins of international trade. Lack of disaggregated foreign data that correspond to trade data (e.g., HS six-digit codes) hampers such analysis. Second, dealing with zero observations may be adjusted. Although the current research assumed missing observations stemming from either one of AFT data or export data as zero, they may just be missing, not zero. Lastly, a proxy for the FTA dummy variable that could explain political ties would also improve the interpretation of the results. We addressed the disparate results appearing from the interaction term with a none-FTA relationship as either the export relationship with a relatively new market or ignorable impact of preferential relationship according to the samples. An instrument that captures political ties between two economies may improve the explanation of the latter. 
Despite the shortcomings mentioned above, our results contribute to the economic development literature as the following. First, the usage of foreign aid from different aid donors has a disparate impact on aid recipients. The summary statistics indicate that the Japanese AFT was relatively concentrated on a specific economy compared to those of the EU. As AFT from the EU showed a consistent and more considerable impact on the trade environment of aid recipients, each government needs to enlarge the pool of foreign aid to a wide spectrum of countries. As the world is becoming more fragmented and globalized, the trade environment of a specific country is affected by its own situation and, at the same time, influenced by the situation of corresponding partners. Thus, foreign aid on more developing countries may result in more extensive opportunities for developing countries to join the production network of the current global economy. Second, regardless of pre-economic or political relationship, AFT boosts the trade environment of the aid recipient either through exploring new markets or fortifying the incumbent relationship. Therefore, grasping the impact of infrastructure that is established due to both tied and untied aids is necessary to evaluate the aid effectiveness even further.

\section{Reference}

Bhagwati, J. N., Brecher, R. A., \& Hatta, T. (1983). The generalized theory of transfers and welfare: bilateral transfers in a multilateral world. The American Economic Review, 73(4), 606-618.

Burnside, C., \& Dollar, D. (2000). Aid, policies, and growth. American economic review, 90(4), 847-868.

Easterly, W. (2006). Reliving the 1950s: the big push, poverty traps, and takeoffs in economic development. Journal of Economic Growth, 11(4), 289-318.

Feenstra, R. C. (1994). New product varieties and the measurement of international prices. The American Economic Review, 157-177.

Feenstra, R. C., \& Kee, H. L. (2008). Export variety and country productivity: Estimating the monopolistic competition model with endogenous productivity. Journal of international Economics, 74(2), 500-518.

Ghimire, S., Mukherjee, D., \& Alvi, E. (2013). Sectoral aid-for-trade and sectoral exports: A seemingly unrelated regression analysis. Economics Bulletin, 33(4), 2756-2762.

Gupta, K. L., \& Islam, M. A. (2012). Foreign capital, savings and growth: An international cross-section study (Vol. 9). Springer Science \& Business Media.

Heckman, J. J. (1979). Sample selection bias as a specification error. Econometrica: Journal of the econometric society, 153-161.

Helpman, E., Melitz, M., \& Rubinstein, Y. (2008). Estimating trade flows: Trading partners and trading volumes. The quarterly journal of economics, 123(2), 441-487.

Hühne, P., Meyer, B., \& Nunnenkamp, P. (2014). Who benefits from aid for trade? Comparing the effects on recipient versus donor exports. The Journal of Development Studies, 50(9), 1275-1288.

Hummels, D., \& Klenow, P. J. (2005). The variety and quality of a nation's exports. American economic review, 95(3), 704-723.

Kim, Y. R. (2012). The effect of aid for trade on export diversification of recipient countries. In ETSG 2013 Birmingham, 15th Annual Conference.

OECD. (n.d.) DAC and CRS code lists. https://www.oecd.org/development/financing-sustainabledevelopment/ (Accessed $8^{\text {th }}$ May. 2021)

Rosenstein-Rodan, P. N. (1943). Problems of industrialisation of eastern and south-eastern Europe. The economic journal, 53(210/211), 202-211.

Rosenstein-Rodan, P. N. (1961). International aid for underdeveloped countries. The Review of Economics and Statistics, 107-138.

Sachs, J. (2005). The end of poverty (Vol. 59). New York: Penguin.

Samuelson, P. A. (1947). Foundations of Economic Analysis. Harvard University Press, Cambridge, MA.

Silva, J. S., \& Tenreyro, S. (2006). The log of gravity. The Review of Economics and statistics, 88(4), 641-658. 
World Bank. (2019). World development report 2020: Trading for development in the age of global value chains. The World Bank.

Yano, M., \& Nugent, J. B. (1999). Aid, nontraded goods, and the transfer paradox in small countries. American Economic Review, 89(3), 431-449.

\section{Appendix}

Appendix A. Corresponding CRS code for AFT Categories

\begin{tabular}{|c|c|}
\hline Aid Type & CRS code \\
\hline Technical Assistance for Trade Policy and Regulations & $33110,33120,33130,33140,33181$ \\
\hline Economic Infrastructure & $\begin{array}{c}21010,21020,21030,21040,21050, \\
21061,21081,22010,22020,22030, \\
22040\end{array}$ \\
\hline Productive capacity building & $\begin{array}{c}24010,24020,24030,24040,24081, \\
25010,25020,31110,31120,31130, \\
31140,31150,31161,31162,31163, \\
31164,31165,31166,31181,31182, \\
31191,31192,31193,31194,31195, \\
31210,31220,31261,31281,31282, \\
31291,31310,31320,31381,31382, \\
31391,32110,32120,32130,32140, \\
32161,32162,32163,32164,32165, \\
32166,32167,32168,32169,32170, \\
32171,32172,32182,32210,3222, \\
32261,32262,32263,32264,32265, \\
32266,32267,32268,33210\end{array}$ \\
\hline Trade-related adjustment assistance & 33150 \\
\hline
\end{tabular}

Source: OECD (n.d.). Rearranged by the author.

\section{Appendix B. Sample Countries}

\begin{tabular}{|c|c|c|}
\hline \multicolumn{2}{|c|}{ Aid Type } & Content \\
\hline \multicolumn{2}{|c|}{ DAC members } & AUS AUT BEL CAN CHE CZE DEU DNK ESP FIN FRA GBR \\
\hline \multirow[t]{2}{*}{$\begin{array}{c}\text { Non-DAC } \\
\text { members }\end{array}$} & $\begin{array}{l}\text { Other } \\
\text { donors }\end{array}$ & $\begin{array}{l}\text { ARE AZE BGR CYP EST HRV ISR KZ KWT LTU LVA MLT ROU } \\
\text { RUS SAU THA TUR }\end{array}$ \\
\hline & $\begin{array}{c}\text { Only } \\
\text { Recipients }\end{array}$ & $\begin{array}{l}\text { ABW AFG AGO ALB ARG ARM ATG BDI BEN BFA BGD BHR, } \\
\text { BHS BIH BLR BLZ BMU BOL BRA BRB BRN BTN BWA CAF, } \\
\text { CHL CHN CIV CMR COG COL COM CPV CRI CUB CYM DJI, } \\
\text { DMA DOM DZA ECU EGY ERI ETH FJI FSM GAB GEO GHA, } \\
\text { GIN GMB GNB GNQ GRD GTM GUY HKG HND HTI IDN IND, } \\
\text { IRN IRQ JAM JOR KEN KGZ KHM KIR KNA LAO LBN LBR LBY } \\
\text { LCA LKA LSO MAC MAR MDA MDG MDV MEX MHL MKD MLI } \\
\text { MMR MNG MNP MOZ MRT MUS MWI MYS NAM NER NGA NIC } \\
\text { NPL NRU OMN PAK PAN PER PHL PLW PNG PRY QAT RWA } \\
\text { SDN SEN SGP SLB SLE SLV STP SUR SWZ SYC TCA TCD TGO } \\
\text { TJK TKM TON TTO TUN TUV TZA UGA UKR URY UZB VCT } \\
\text { VEN VNM VUT WSM YEM ZAF ZMB ZWE }\end{array}$ \\
\hline
\end{tabular}

